\title{
CRUZANDO FRONTEIRAS NA \\ SOCIEDADE DA DESINFORMAÇÃO: \\ a busca dos refugiados por cidadania
}

\section{CROSSING BORDERS WITHIN DISINFORMATION SOCIETY: the refugee search for citizenship}

Bruno Macedo Nathansohn ${ }^{1}$

Anna Cristina Brisola

\begin{abstract}
RESUMO
A ampliação do acesso e a difusão de informações não colaborou com a paz, segurança e liberdade, não evoluiu para a globalização da solidariedade, da comunhão e do livre fluxo de pessoas. Pelo contrário, as nações emergentes comercialmente e os fluxos pelas fronteiras são tratados, cada vez mais, como um problema e ameaça. Diante deste cenário, o presente artigo procura desenvolver uma análise a partir da identificação de relações entre as migrações humanas e modelos de desinformação, a fim de colaborar com a discussão sobre a busca dos refugiados por cidadania. Trata-se de articulação analítica entre dados coletados de uma pesquisa e os conceitos de desinformação, de natureza qualitativa e de caráter bibliográfico. A partir de narrativas coletadas em um centro de acolhida de refugiados e solicitantes de refúgio, na Cidade do Rio de Janeiro, procura-se relacioná-las às chamadas táticas de desinformação, evidenciando sua influência nos processos de acolhimento humanitário e na luta por cidadania dos refugiados. A consciência sobre as consequências fomentadas pela desinformação desmonta distorções informativas, colaborando para a transformação social como um todo.

Palavras-Chave: Refugiados. Disinformação. Migração. Cidadania.
\end{abstract}

\begin{abstract}
Expanding access and disseminating information have not contributed to peace, security and freedom, nor have it evolved into the globalization of solidarity, communion and the free flow of people. In contrast, commercially, emerging nations and border flows are increasingly treated as a problem and threat. Given this scenario, the present article seeks to develop an analysis based on the identification of relationships between human migrations and models of disinformation, in order to collaborate with the discussion about the refugees search for citizenship. It is an analytical articulation between data collected from a research and the concepts of misinformation, of qualitative nature and bibliographic character. From narratives, which were collected at a refugee and refugee requesting center in the city of Rio de Janeiro, we seek to relate them to the so-called disinformation tactics, highlighting their influence on the humanitarian reception processes and the refugees search for citizenship. Awareness of the consequences fostered by misinformation dismantles informational distortions, contributing to the social transformation as a whole.
\end{abstract}

Keywords: Refugees. Desinformation. Migration. Citizenship.

Artigo submetido em 11/01/2020 e aceito para publicação em 13/09/2020

1 Doutor em Ciência da Informação pela Universidade Federal do Rio de Janeiro, Brasil. Programa de Atendimento a Refugiados e Solicitantes de Refugiados da Cáritas,Arquidiocesana do Rio de Janeiro, Brasil. ORCID: https://orcid.org/0000-0002-3136-1007. E-mail: bnathansohn@gmail.com

2 Doutoranda em Ciência da Informação. Instituto Brasileiro de Informação em Ciência e Tecnologia, Brasil. Universidade Federal do Rio de Janeiro, Brasil. ORCID: https://orcid.org/0000-0002-4349-128X. E-mail: anna.brisola.jor@hotmail.com 


\section{INTRODUÇÃ̃O}

0 atual ambiente digital ampliou 0 acesso às informações dos mais variados tipos, difundindo uma quantidade de informações que transcende classes sociais, atores políticos e regiões diversas do globo. Esse cenário incentivou o conceito de Sociedade da Informação, pelo valor conferido à informação na contemporaneidade, os modos de produção, o valor capital da informação além daquele ensejado por ela e o poder comprovado que a informação possui. Contudo, com o avultamento e a complexificação dos problemas que vêm causando distorções e distopias informacionais, à esta Sociedade da Informação se adere a Sociedade da Desinformação. São exemplos de causas dessas distopias informacionais, a desinformação e fake news, firehosing, boatos, teorias da conspiração, deepfake.

- FakeNews: Fake News sãoartigos ou informações com características de notícias intencionalmente e verificadamente falsos, que podem enganar os leitores. São notícias fabricadas, com características jornalísticas, mas antecipadamente pensadas para a manipulação e descoladas da verdade. Elas possuem características bem específicas de produção, formatação e intenção. Baseada em Allcott e Gentzkow (2017, p. 213);

- $\quad$ Firehosing: Tática que faz analogia com firehose (mangueira anti incêndio). Que inunda propositalmente o usuário exclusivamente através de fake news;

- Boatos: Boatos e rumores não possuem origem em uma determinada notícia ou informação, nem uma intenção específica de influência política, econômica, social etc. são fenômenos antigos, que podem ser criados de má-fé ou não, mas não possuem origem ou formato noticioso e por isso não se configuram como fake News;

- Teorias da conspiração: Teorias que não são facilmente verificáveis ou desmentidas. Normalmente se originam em pessoas que acreditam em sua veracidade e são baseadas em pontas soltas de fatos reais ou de crenças enraizadas contextualizadas ou descontextualizadas;

- Deepfake: Com ajuda de programas avançados de animação e inteligência artificial, são executados vídeos e áudios manipulados, capazes de ludibriar quem assiste. Podem ser tão aproximados do real que 0 indivíduo tem dificuldade de distinguir como algo produzido artificialmente.

E as causas dessas distopias são: hiperinformação, hipervelocidade da informação, a falta de aderência com a verdade, afastamento da ciência, pós-verdade e a ética em relação à informação. 
0 conceito de desinformação, seu ambiente facilitador e seus mecanismos utilizados neste trabalho são frutos da compilação e adequação didática de diversos autores que tratam do tema, elaborada por Anna Brisola e Andréa Doyle (no prelo). Os autores que serviram de base ao estudo citado são: Volkoff (1999), Parenti (2001), Abramo (2003), Serrano (2010), Chomsky (2014) e Christofoletti (2018).

Nesse contexto, consideramos que a

Desinformação envolve informação descontextualizada, fragmentada, manipulada, retirada de sua historicidade, tendenciosa, que apaga a realidade, distorce, subtrai, rotula ou confunde. A desinformação neste sentido não é necessariamente falsa; muitas vezes, trata-se de distorções ou partes da verdade. (BEZERRA, 2018)

A globalização dos anos 1990, prometendo paz, segurança e liberdade nas trocas comerciais, não evoluiu para a globalização da solidariedade, da comunhão e do livre fluxo de pessoas. Pelo contrário, as nações emergentes comercialmente e os fluxos pelas fronteiras são tratados, cada vez mais, como um problema e ameaça. Como aponta Marshall (2017, p.10, tradução nossa), "os padrões no capitalismo da informação estendem e intensificam esses problemas comunicativos, e esses padrões podem ser manipulados com relativa facilidade por aqueles que acham útil a hostilidade, 0 apartamento, a dicotomia e a falta de comunicação".

Nesse cenário encontra-se a questão dos migrantes e a compreensão que se faz sobre a situação de pessoas em fuga de seus países de origem. Atrelados à uma visão hegemônica de cunho nacionalista e às políticas de retomada de uma agenda de natureza neocolonialista, as pessoas em situação de refúgio e os imigrantes que foram elegíveis nos países de destino, são vistos como ameaças em potencial. Prevalece uma biopolítica de controle dos corpos em movimento, por meio de dispositivos de vigilância, monitoramento e controle (FOUCAULT, 1987, 2008, 2010). Tudo isso, apesar dos esforços de movimentos sociais transnacionais, agências e órgãos supranacionais, organizações não-estatais e iniciativas de alguns Estados.

Muros físicos são erigidos para a contenção dos fluxos migratórios, ao mesmo tempo em que barreiras simbólicas, baseadas em discursos, narrativas e decisões políticas comunicadas, criam 0 ambiente para o estabelecimento de uma determinada ideia preconceituosa a respeito dos refugiados, tentando excluí-los do acesso a direitos. Essas ideias são sustentadas por informações que perpassam de documentos oficiais aos meios de comunicação. Assim, consideraremos a influência da desinformação sobre os refugiados e a influência destas em sua busca por cidadania. 


\section{FLUXO DE PESSOAS, A INFORMAÇÃO, A DESINFORMAÇÃO E A CIDADANIA}

Considerando os fatores levantados na introdução, a busca de pessoas apátridas por cidadania enfrenta a resistência de diversos grupos ao longo dos países pelos quais passam. Assim, essas pessoas não podem contar com a cidadania proporcionada pelos Estados nos quais buscam refúgio. Algum grau de cidadania é alcançado por meio de leis e normas constituídas na relação entre Estados e agências supranacionais, entretanto nos países-destino os indivíduos não conseguem elegibilidade.

A estrutura legal que tenta abarcar as necessidades de pessoas em trânsito, na maioria dos casos indocumentadas, assenta-se na Declaração Universal dos Direitos Humanos, da carta da ONU, de 1948; no Estatuto do Refugiado, de 1951; e do Protocolo de 1967. Além da letra jurídica, uma certa governança vem sendo constituída através comissões de direitos humanos continentais, como: Comissão Interamericana de Direitos Humanos, da Organização dos Estados Americanos (OEA); Comissão Africana dos Direitos Humanos e dos Povos (ACHPR, na sigla em inglês); Corte Europeia de Direitos Humanos (ECHR, na sigla em inglês).

Destaca-se, dentre todos esses mecanismos de proteção, o Protocolo de 1967 relativo do Estatuto dos Refugiados, pois foi por meio deste que o Estatuto dos Refugiados, oriundo do pósGuerra foi ampliado. Neste documento apresenta-se claramente a necessidade dos Estados-Partes em cooperar com o Alto Comissariado das Nações Unidas para os Refugiados (ACNUR), como se segue abaixo:

[...] §1. Os Estados-Membros no presente Protocolo, comprometem-se a cooperar com o Alto Comissário das Nações Unidas para os Refugiados ou qualquer outra instituição das Nações Unidas que Ihe suceder, no exercício de suas funções e, especialmente, a facilitar seu trabalho de observar a aplicação das disposições do presente Protocolo. (ACNUR, 1967)

No entanto, o que vem se repetindo é a prevalência de decisões autônomas de governos, calçadas mais na discricionariedade dos mandatários do que em políticas de Estado, ou seja, contrariando acordos e tratados internacionais. Esse é o caso do Brasil, com as mudanças na nova Lei de Migração, $n^{0} 13.445 / 17$, que veio a substituir o Estatuto do Estrangeiro (Lei $n^{0} 6.815 / 80$ ).

Para se chegar à nova Lei de Migração, houve um crescente processo de conscientização que teve, num primeiro momento e, de certa forma, mantém-se, a construção de uma imagem dos imigrantes como um risco e uma ameaça. Essa era a lógica do Estatuto do Estrangeiro, que se baseava numa perspectiva nacionalista e securitária. Pressupostos davam conta de que havia uma hierarquia discriminatória no tratamento do estrangeiro em relação aos nacionais. 
Essa visão alimentava-se por uma série de valores conservadores que se mantinham, de uma certa forma, desde as políticas de povoamento da época do Brasil Império. Alimentar determinada visão sobre o estrangeiro que busca viver no Brasil vem sendo parte de uma estratégia securitária que expressa o risco de perda da soberania nacional. Mesmo considerando que a questão securitária é de fundamental importância, para a minimizar o risco de entrada e consolidação de redes de criminosos e terroristas.

Serrano (2010, p.45) observa o abuso do termo "terrorista" pelos meios de comunicação e sublinha que "a linguagem também é utilizada para ofuscar as origens e as razões dos acontecimentos. Não apenas o discurso ignora esses elementos, mas, além disso, tenta afastá-los para que o público não tenha a tentação de perguntar sobre eles". Expressões como "os combates explodiram na região" e "morreram quatro pessoas nos tumultos", não remontam o cenário dos acontecimentos, não tratam das origens ou motivações e afastam os desconfortos de explicar que as pessoas não morreram, foram mortas.

Analisando o silêncio na primeira página, referindo-se às manchetes dos meios de comunicação, Serrano (2002, p. 62) denuncia que os meios de comunicação aplicam a lógica do interesse de que um determinado assunto participe da agenda política ou social ao dar destaque ou silenciá-lo em suas notícias. Serrano exemplifica com a realidade de seu país, a Espanha, relacionando as respostas sobre terrorismo e imigração às perguntas "Problemas principais da Espanha" e "Problemas que mais Ihe afetam", que nunca concordam entre si.

É essa a razão para que o terrorismo ou a imigração alcancem uma maior importância quando se pensa a respeito dos problemas da Espanha, mas não, entretanto, como problema que afeta a quem responde. Nesta segunda ocasião, os temas que ocupam posições são "os problemas de índole econômica" ou "a moradia". Sem dúvida, são os meios os que, com a sua política de agenda/primeira página, conseguem que 0 cidadão considere que é mais importante 0 terrorismo que a moradia. (SERRANO, 2002, p.62)

Chamamos o conjunto destes mecanismos de "parcialidade dissimulada" que inclui "desproporção", "hierarquização", "etiquetagem", "fontes e analistas parciais", "partes iguais" e escamoteamento". Chomsky (2014) chama a consequência dessa técnica de "percepção seletiva". 0 destaque é conferido segundo os interesses. Aqueles que corroboram ou colaboram ganham destaque; os que confrontam, revelam erros ou fragilidades do sistema são silenciados. As notícias e informações desinteressantes são barradas, silenciadas e, consequentemente, apagadas. Assim, 0 caso dos imigrantes é comumente associado à imagem que corrobora as atitudes de acolhimento ou não, de acordo com os interesses dos poderes hegemônicos daquele país ou bloco. 
No entanto, a hierarquia de prioridades deve posicionar o princípio da dignidade humana no topo da pirâmide, sendo a questão da segurança aprimorada para minimizar riscos que enfrentamos no dia-a-dia, com ou sem a presença de estrangeiros em território nacional. As técnicas devem ser as mesmas utilizadas para solucionar qualquer tipo de crime, independente dos elementos partícipes de potenciais ilícitos.

Criar um problema para depois solucioná-lo é outra característica da desinformação. 0 caso de Saddam Hussein é lembrado por Serrano (2010) como exemplos desse tipo de mecanismo de desinformação, tratando de terrorismo e guerra. Depois de anos como aliado dos EUA, o ditador iraquiano se transforma em um inimigo detestável e perigoso. A acusação de produção de armas químicas, fomentou o apoio e incitou os ataques e bombardeios. Ainda que a informação tenha sido desmentida posteriormente, isso não modificou o fato de que a guerra já estava ganha, o problema solucionado e o rótulo aderido.

Esta tática é antiga e se repete muitas vezes em épocas, lugares e com objetivos diversos. Chomsky (2014, p.7), comenta a operação de propaganda política utilizada pelo governo do presidente Wilson, para conseguir aprovação da população da adesão dos EUA à Primeira Guerra Mundial demonizando alemães. Hitler repetiu em sua perseguição aos judeus e Wilson, novamente, para hostilizar os movimentos trabalhistas nos EUA. Foi prática comum durante a Guerra Fria e hoje se propaga de uma maneira incrível nas dicotomias políticas das eleições locais, em várias partes do globo.

Portanto, no caso tratado aqui, o que está em jogo é o uso de uma série de termos que insistentemente colocam o imigrante como risco iminente. Não qualquer imigrante, mas sempre aquele em condição de vulnerabilidade, mormente em situação considerada irregular, leia-se, refugiado. Nesse ponto é importante considerar o papel da desinformação como fator desqualificador do imigrante. Apesar de haver, de fato, uma mudança considerável da grande mídia em relação ao tema das migrações, o processo de desinformação continua forte, tornando-se uma barreira para a consecução de uma governança migratória satisfatória.

Um exemplo de desinformação pode ser demonstrado pela pesquisa apresentada em junho de 2018, pelo professor Leandro de Carvalho, da Universidade de Brasília, intitulada "Caminhos para o Refúgio: Inserção Produtiva e Social de Refugiados"3. Nessa pesquisa demonstra-se como a

3 Entrevista publicada em MigraMundo, por Rodrigo Borges Delfim, em 19 de junho de 2018. 
desinformação continua sendo uma barreira para compreensão mais adequada da questão do refúgio e sobre o refugiado.

Um dos resultados aponta a forma de recrutamento de refugiados para trabalharem nas empresas, que associam o tipo de imigrante a determinadas qualidades físicas e intelectuais estabelecidas de maneira estereotipada. Nesse sentido, africanos e centro-americanos relacionam-se à "força física" e "aceitar menores salários no início", enquanto profissionais de origem europeia são relacionados à "capacidade de liderança" e "criatividade".

Novamente pode ser detectado mais um mecanismo de desinformação - a etiquetagem. Este mecanismo "cola" significados positivos ou negativos que conferem de antemão uma imagem ao rotulado. Com o uso, bem comum, deste artifício, as informações carregam estereótipos em etiquetas simplificando e distorcendo o entendimento a respeito de uma realidade, povo ou indivíduo, que 0 leitor/usuário não pode presenciar ou conhecer.

0 objetivo deste artifício é formar e reforçar no usuário/leitor da informação, antecipadamente, uma determinada percepção intencionada. Se a intencionalidade é rotular negativamente, associa-se determinado fato ou grupo a uma palavra que causa repulsa, medo ou recusa. É o caso da associação usual carregada na expressão "terrorista islâmico", que confere a todos os seguidores desta religião, estendendo-se a toda comunidade árabe do mundo, o rótulo de terrorista. Fato que vem afetando as imigrações de maneira notória, com mais cerceamento, monitoramento, vigilância e controle de pessoas e fronteiras.

Essa tendência reforça o que foi consolidado como políticas de Estado e convencionado pela mídia em geral, ao longo de séculos. A visão que é formada sobre o refugiado é a medida exata do estranhamento conferido pela visão nacionalista conservadora em relação ao "Outro", aquele estrangeiro ameaçador, alimentada pela desinformação dos meios de comunicação tradicionais e potencializada hoje em dia pelas mídias digitais.

Dessa forma, os termos utilizados para etiquetar e se referir aos refugiados variam da desqualificação à invisibilidade. Se, num primeiro momento, os sírios podem ser vistos e apontados pelo senso-comum, como "terroristas", num outro, pela coesão e longa presença de próspera comunidade síria no Brasil, esses estereótipos são superados, e mecanismos legais são rapidamente implementados para beneficiar esse grupo. Ao contrário dos congoleses e angolanos, por exemplo, que são invisibilizados pelos tomadores de decisão, pois só encontram proteção em redes de solidariedade entre eles mesmos. 
Assim, a terminologia utilizada comumente pelo senso-comum para se referir aos refugiados revela desinformação clara, que esconde questões estruturais reprodutoras de vulnerabilidade social, política e econômica, como bem salienta uma entrevistada na pesquisa realizada no Programa de Atendimento a Refugiados e Solicitantes de Refúgio, da Cáritas Arquidiocesana do Rio de JaneiroPares/CARJ ${ }^{4}$.

[A] mídia tem importante papel sobre a publicização do conflito na Síria, mas sobre o Congo, só existem informações pelas ONGs. Porque a guerra no Congo transcende a questão local/ nacional. É a expressão de uma guerra global por recursos. Morre-se muito mais pessoas no Congo do que na Síria, no dia-a-dia, independente do conflito. 0 problema da África é a colonização. Houve uma reforma da colonização. A colonização se mantém até hoje. Apoio externo a determinados governos, que fazem a política que as potências desejam (Malala, 38 anos - informação oral registrada por escrito) [Malala, 38 anos] (NATHANSOHN, p. 197, 2018).

A terminologia utilizada pelo senso-comum, que é reforçada pelas instituições, influencia modelos de classificação sobre os refugiados. A visão do cidadão comum brasileiro e de setores da burocracia estatal, como o Departamento de Polícia Federal - DPF, sobre os refugiados expressa-se pela forma como denominam o congolês, que chamam de "angolano". Perguntado sobre a mentalidade da sociedade brasileira, e da burocracia estatal, especificamente, em relação aos refugiados, o respondente Carlos, 42 anos, diz que

[a] sociedade brasileira de um modo geral, infelizmente, ignora muito 0 tema de refúgio. Muitas pessoas confundem mesmo. Acham que o refugiado é um foragido, um fugitivo...é mais essa confusão, das palavras mesmo...desinformação, desconhecimento. Acaba discriminando a pessoa sem querer. "Angolano", como chamam a gente aqui no Rio. Aqui nos chamam a todos de "angolanos". Até mesmo a Polícia faz essa confusão. Mas é a população geral do Rio. A Polícia também faz parte da população, então...trabalhando lá, não separa eles da população geral...faz parte, são povo. Os cariocas chamam todos os africanos de "angolanos", até mesmo os haitianos [são chamados também de angolanos]. Aqui não chamam a gente muito de africano não. É mais de "angolano". Essa confusão que as pessoas fazem de Angola com África, entendeu? Abrangendo as coisas, tentar resumindo as coisas, lá atrás muito preconceito. Basta só um errar, todo mundo vai pagar por isso. Isso acontece muito na PF ... porque o refugiado também é um ser-humano qualquer, normal...como todo o ser-humano faz coisa errada, o refugiado também faz coisa errada, igual a todo mundo. Um refugiado também faz coisa boa, igual a todo mundo. Mente, se preocupa pela vida como qualquer pessoa. Então também pode acontecer com um refugiado fazer uma coisa errada. Mas como infelizmente já tem essa visão de que a gente é uma coisa só, aí o preconceito será geral, pra todo mundo. Isso acontece muito na Polícia Federal. Basta só uma pessoa, seja de qualquer nacionalidade. Se é de pele negra pra eles, já é um "angolano", e um "angolano" somos nós todos, aí todos temos que pagar. Mas, engraçado é que quando um "angolano"... segundo eles, né? Um "angolano" de pele negra que fala com sotaque, faz uma coisa excelente, não vai recompensar todo mundo. Só a coisa ruim que é propagada. Aí é que vai ser até uma "música" pra eles lembrarem. "Ah, ontem vc. já veio aqui e fez isso e isso. Vocês são assim...". Então, essa é a diferença [entre a] Cáritas [e a] PF [Carlos, 42 anos] (NATHANSOHN, p. 199, 2018).

4 Entrevista realizada para pesquisa de tese, pelo PPGCI do convênio IBICT-UFRJ, defendida em abril de 2018. Para preservação da identidade do entrevistado, seus nomes são mantidos em sigilo, optando pela criação de nomes fictícios. 
0 ideário reproduzido pelo senso comum pode gerar uma coerção social da sociedade que recebe refugiados, produzindo nos próprios refugiados um autoconvencimento sobre sua condição atávica (i.e. colombiano = traficante), que é naturalizada pela sociedade geral do país receptor, reforçando preconceitos do senso-comum e, consequentemente, das pré-classificações impostas fora do âmbito jurídico. Aspecto que pode influenciar o tratamento e legitimar tomadas de decisão da burocracia estatal ligada à área de segurança. Uma dessas pré-classificações, para depois permitir o prosseguimento do processo de admissibilidade do solicitante, também foi ponto levantado por um dos entrevistados.

Mas tem um movimento, especialmente pela Polícia Federal, de dizer que a [própria] PF deveria fazer um "Juízo de Admissibilidade" pra pedido de refúgio...quer dizer, a Polícia Federal abriria uma instância a priori de avaliar a situação do solicitante, para saber se 0 solicitante pode pedir refúgio ou não. Quer dizer, antes de efetivar o pedido de refúgio, a Polícia Federal vai fazer uma prévia análise sobre a possibilidade de exclusão do refugiado sobre eventual ameaça ou sobre a falta de motivação do pedido de refúgio, ou seja, a Polícia Federal faria um filtro, pautada com uma preocupação de segurança, pra ver quem vai fazer o pedido, ou não [AZMAR, 42 anos] (NATHANSOHN, p.216, 2018).

Segundo o relatório “A desinformação - contexto europeu e nacional”, publicado em 04 de abril de 2019, pela Entidade Reguladora para a Comunicação Social - ERC, a desinformação "é suscetível de semear desconfiança nas pessoas e alimentar tensões sociais, chegando, no limite, a representar ameaças à segurança interna, incluindo processos eleitorais".

Percebe-se que a informação a respeito dos refugiados, migrantes e imigrantes sofre influência da desinformação e também é, por vezes, desinformativa, na medida que descontextualiza, fragmenta, distorce, subtrai, rotula e até distorce as informações sobre os indivíduos e os povos.

Assim, evidencia-se a existência de uma relação clara entre os cenários e mecanismos de desinformação desenvolvidos por Brisola e Doyle (no prelo), e os relatos sobre os refugiados, registrados na pesquisa de doutorado de Nathansohn (2018). Em termos contextuais, destacam-se alguns mecanismos abaixo:

A "hiperinformação", neste caso, traduzida pelo grande volume de informação em que o que realmente importa não aparece, por causa de um apagamento pelo excesso. A crescente profusão de informações e a facilidade de acesso de inúmeras fontes, contribuem para uma enxurrada de informações, nebulizando a informação que realmente importa, ou mesmo confundindo o leitor, telespectador ou internauta.

Também colaboram com 0 apagamento, e com as outras questões relacionadas neste artigo, os mecanismos de desinformação "orientação" e "desorientação" (BRISOLA; DOYLE, no prelo). A "orientação" trata da argumentação para conduzir a opinião pública a apoiar determinada conduta. 
"Submetido, ora mais, ora menos, mas sistemática e constantemente, aos demais padrões de manipulação, o leitor é induzido a ver o mundo como ele não é, mas sim como querem que ele 0 veja" (ABRAM0, 2003, p.49). A orientação é facilitada pelo acúmulo de ideias, conceitos e "verdades" veiculadas na desinformação sistemática, porém não óbvia.

Esse mecanismo perpassa toda a produção e difusão da informação e pode abarcar diversas informações e fontes. A "desorientação" é caracterizada por informações apresentadas de forma incompreensível, descontextualizada e com pontos de vista e escolhas tendenciosas. Raramente explicam os problemas subjacentes nem os motivos e condições sociais envolvidos. São oferecidos alguns números, mas outros são silenciados. "Palavras e conceitos são usados conscientemente para violar a capacidade cognitiva das grandes massas da população, para confundir as mentes e, finalmente, para impor significados que contradizem a realidade" (ROMANO, 2007, p.116).

Quando o tema das migrações surge com maior força na mídia internacional, ela surge em meio a outros acontecimentos de impacto, com intervenções de cunho neocolonialista no Oriente Médio (Síria, Palestina, lêmen etc.) e no Norte da África (Líbia), além da grave crise financeira de 2008 e mobilizações para a mudança de regime, na Ucrânia, e com a Primavera Árabe. Todas essas irrupções contribuíram diretamente para que milhões de pessoas deixassem suas casas, famílias, cidades e mesmo regiões, para buscarem abrigo em outros lugares. Apesar de uma minoria deslocarse para a Europa, a ideia de segurança persiste, apontando o migrante como uma ameaça à paz e à segurança. Pode-se dizer que havia um discurso único produzido pela mídia ocidental, mostrando-os como invasores perigosos, potencialmente criminosos e terroristas.

Muito da visão que se faz do migrante refugiado é de alguém que busca tirar vantagem das conquistas sociais e econômicas alcançadas graças à competência dos europeus. 0 sentimento de superioridade da civilização de origem européia ocidental, conduz à uma refutação de seu próprio envolvimento na condição de miserabilidade de povos que foram colonizados e classificados como inferiores, atrasados, selvagens e incapazes. Portanto, o que prevalece é a lógica da segurança, do que chamam hoje de "Fortaleza Europa" contra aqueles considerados pobres, incultos, tradicionalistas, em última instância fundamentalistas religiosos, e de pessoas resistentes à cultura e aos hábitos da sociedade receptora.

0 “conhecimento privilegiado", baseado em algoritmos, vigilância, registros etc., é mais um exemplo de cenário propício à desinformação, onde quem domina a produção e o fluxo da informação são as grandes empresas, que sabem mais que os governos, e que, por sua vez, sabem mais que 
indivíduos, uns sobre os outros, é outra característica desse contexto. A informação sobre leis, trâmites burocráticos etc. é praticamente inacessível aos migrantes, pois a situação exige, inicialmente, o conhecimento da língua como princípio básico para entender o processo e acessar as normas que regem a solicitação de refúgio e a legislação, em seu conjunto de direitos e deveres.

Dessa forma, constroem-se formas alternativas de acesso ao conhecimento pelos grupos de migrantes, que se organizam como quistos culturais, mantendo suas tradições, hábitos, idiomas e religiões. Em algumas situações, se for um grupo homogêneo em relação a posicionamento político, valorizam a coesão ideológica também. A partir de uma organização mínima, esses diversos grupos começam a criar canais de comunicação com pessoas-chave de organizações não-estatais que tratam do acolhimento e dos procedimentos jurídicos e sociais de solicitação de refúgio. Advogados e assistentes sociais, por exemplo, que cuidam do atendimento e acompanham todo o trâmite da solicitação, acabam por ser a fonte mais segura e confiável de informação para solicitantes e refugiados, tendo em vista as dificuldades impostas pela estrutura burocrática estatal, principalmente pelos órgãos de controle de entrada e saída do território nacional, como no caso brasileiro do DPF.

0 estímulo da complacência com a mediocridade, por um "nivelamento" por baixo de saberes, traduz-se pela "ignorância ostentação" que toma conta das redes sociais digitais e que também propicia a desinformação. Dados e pesquisas estatísticas já não são instrumentos que detêm o poder de persuasão, permitindo a análise racional e a compreensão da realidade. A ciência passa a ser vista pelo senso comum, e de forma imediatista, como um campo incapaz de explicar, fazer compreender e resolver as questões práticas da vida social. Então, valendo-se da vivência e da experiência empírica, qualquer um, independente do nível de estudo que ostenta, acredita ter a capacidade de apresentar suas explicações sobre quaisquer fenômenos sociais e políticos, com autoridade. As TIC contribuem diretamente para a disseminação destes falsos saberes, pois a profusão de fontes de informação é tão capilar, pulverizada e ubíqua, que se torna difícil, mesmo para alguém com certo grau de estudo, verificar a sua veracidade.

Portanto, todos os medos gerados pelos meios de comunicação de massa, incluindo a Internet, sobre a falsa notícia de uma possível chegada de navios repletos de imigrantes refugiados para 0 Brasil, se o Partido dos Trabalhadores - PT continuasse no poder; que médicos cubanos estariam atuando no Brasil como espiões; ou que haitianos estariam invadindo o Brasil, foram repercutidas como verdades. As causas dos fenômenos nunca são examinadas a fundo, estudos científicos são vistos como manipulações enganosas porque seriam uma forma de determinados grupos justificarem 
suas ideologias. Então, nada mais razoável, nessa linha de raciocínio, do que se informar e formular teorias por meio de qualquer fonte disponível na web e compartilhada por amigos e familiares. Nesse contexto, destacam-se alguns mecanismos de desinformação:

A infantilização da informação transmitida é de fácil entendimento, sucinta, sem contrastes e descontextualizada, o que provoca fácil esquecimento. Nessa perspectiva, se o estrangeiro chega ao Brasil demonstrando vulnerabilidade de qualquer ordem, ele pode ser visto como ameaça de diversos tipos, a contar por seu país de origem, situação social e cor de pele. Ao mesmo tempo, se houver reações de rechaço muito extremadas, isso também pode gerar o efeito contrário por parte da população e 0 estrangeiro passa a ser protegido ao extremo, em que qualquer coisa que faça para sobreviver é visto como um exemplo de empreendedorismo salutar utilizado pelos meios de comunicação para mascarar causas estruturais para sua situação de vulnerabilidade.

Disso, dependeria seu esforço individual, reverberam as mídias de ideologia liberal, independentemente do contexto social que o receba, com seus comportamentos e modelos mentais específicos. Na verdade, situações que deveriam ser vistas como distorções no trato da dignidade humana e, portanto, deveriam ser compreendidas como uma questão estrutural do modelo de sociedade onde vivemos, é colocada como um valor positivo e normalizado a ser superado de maneira individual. Nesse aspecto, tanto o sucesso quanto o fracasso do indivíduo são vistos como fruto de seu próprio esforço e escolhas pessoais, e não como resultado de uma situação complexa, construída a partir de modelos políticos, sociais e econômicos que induziram grandes contingentes populacionais a passarem por experiências coletivas, guardadas as devidas exceções.

Cabe nessa realidade a técnica de desinformação que nomeamos de "culpabilidade". Nesse tipo de desinformação é conferido ao indivíduo ou ao grupo a culpa pelo fato ou problema, a responsabilidade por sua condição ou pelas consequências. Uma frase recorrente dos setores mais conservadores brasileiros na atualidade é "não tem o que comer, ou é pobre, porque não quer trabalhar". Essa frase representa o cerne da culpabilidade e foi alimentada por muita desinformação. Não se trata de falta de emprego, divisão de classe, abismo social, exploração, acumulação do capital nas mãos de pouquíssimos, falta de assistência social, recessão e mais inúmeras causas que poderíamos apontar; a questão é a falta de vontade, a responsabilidade é exclusiva do indivíduo. Essa imputação de responsabilidade pode ser tão bem feita que o próprio indivíduo a assume como verdade.

A comoção, segundo Brisola e Doyle (no prelo), é um mecanismo que captura o aspecto emocional. Discursos de ódio ao estrangeiro emergem pela simples presença do imigrante no espaço 
público, provocando reações nacionalistas em defesa dos empregos para os brasileiros, por exemplo. A percepção do senso-comum de que a falta de empregos está associada à "invasão" de estrangeiros, e que imigrantes pobres só fazem aumentar a pobreza.

A despeito da mudança de discurso da mídia corporativa sobre a questão migratória, cobrindo reportagens em maior profusão e qualidade sobre a situação dos migrantes, apresenta-se um migrante sempre apto ao mundo do trabalho. Discute-se sempre sua situação em sua face econômica. 0 migrante é sempre útil como mão-de-obra de reserva. Assim, a bondade do discurso recai inevitavelmente na possibilidade do migrante ser um empreendedor ou alguém que pode ser, se assim permitirem as empresas, uma força de trabalho, reforçando o medo dos locais em relação a concorrência pelos empregos disponíveis.

0 problema desse tipo de cobertura é que, invariavelmente, anula o verdadeiro sentido da proteção humanitária, que é a preservação da dignidade humana, o que inclui, é claro, o mundo do trabalho, mas não pode ser restrito a isso. A proteção humanitária, em teoria, transcende a perspectiva meramente utilitária do ser-humano como força de trabalho, como apregoado pelo discurso neoliberal. Talvez, por isso, tenha-se tanta dificuldade em estruturar uma governança migratória global.

0 regime de informação, coordenado e orientado pelos centros de poder global, fundamentalmente ligados aos centros de reprodução do capital sem pátria, pode funcionar de maneira oposta à agenda humanitária, pois onde há mais interesse do capital, menos proliferam princípios e valores humanitários.

\section{CONSIDERAÇÕES FINAIS}

Fica clara a relação imbricada entre a luta por cidadania dos refugiados e a desinformação, na qual a segunda interpõe-se como obstáculo à primeira. Sem considerar a importância nociva da desinformação no processo de acolhimento dos refugiados, os direitos humanos destes seguirão embotados. Como visto, os fenômenos decorrentes da desinformação permeiam inclusive as instâncias estatais incluindo os órgãos de segurança como relatado pelos entrevistados. Esta condição se estende para além das leis ou regulamentações que possam afetar os refugiados, alcançando os possíveis empregadores, agências de empregos, população geral e eles mesmos.

A consciência das consequências fomentadas pela desinformação é um primeiro passo para mudança na realidade instável destas pessoas. Compreender a diversidade de origens, etnias, culturas e crenças, mas também de indivíduos. Como apontou Carlos, 42 anos (NATHANSOHN, p. 199, 2018) 
tão propriamente, "chamam a todos de 'angolanos", inclusive a polícia, "Basta só um errar, todo mundo vai pagar por isso", "Mas, engraçado é que quando um "angolano"...segundo eles, né? Um "angolano" de pele negra que fala com sotaque, faz uma coisa excelente, não vai recompensar todo mundo. Só a coisa ruim que é propagada".

As etiquetas também aderem em muito mais que um indivíduo ou uma nacionalidade. Todos os árabes são identificados com sírios ou libaneses, grandes comerciantes ou terroristas. Os orientais são inteligentes, mas se são pobres, são todos iguais, fazem pastel, são porcos e usam mão de obra escrava. Todo negro é africano. Os estereótipos são reforçados por estas etiquetas e suas consequências positivas ou negativas ganham espaço nas decisões e oportunidades para cada indivíduo, sem respeitar nenhuma individualidade e ampliando ou restringindo as possibilidades de adequação, prosperidade e acolhimento no novo país.

Faz-se necessário um aprofundamento das pesquisas que possam identificar os entraves causados pela desinformação nos processos legais, sociais e culturais que envolvem os refugiados, bem como promover informações que desmistifiquem as etiquetagens e preconceitos aderidos que prejudicam o acolhimento, a prosperidade e a cidadania dos indivíduos refugiados. Somente desta maneira as promessas de paz, de uma globalização da solidariedade, da comunhão e do livre fluxo de pessoas, poderão receber algum sopro de esperança.

\section{REFERÊNCIAS}

ABRAM0, Perseu. Padrões de manipulação na grande imprensa. $2^{a}$ ed. São Paulo: Fundação Perseu Abramo, 2003.

BERNER, V. 0 fluxo migratório mundial e o paradigma contemporâneo de segurança migratória. Revista Versus, v.3, p. 68 - 78, 2009.

BRASIL. Constituição Federal. (1988). Disponível em: http://www.planalto.gov.br/ccivil_03/ constituicao/constituicao.htm. Acesso em: 30 mar. 2017.

BRASIL. Estatuto do Estrangeiro. Disponível em: https://www2.senado.leg.br/bdsf/bitstream/handle/ id/508142/000986045. pdf?sequence=1. Acesso em: 30 jul. 2019.

BRASIL. Nova lei de migração. Disponível em: . Acesso em: 30 jul. 2019.

BRISOLA, Anna Cristina; DOYLE, Andréa. Critical information literacy as a path to resist "fake news": understanding disinformation as the root problem. Open Information Science, (No prelo) 
CHOMSKY, Noam. Mídia: propaganda política e manipulação. Tradução: Fernando Santos. Ed. Martinsfontes. São Paulo. 2014.

CHRISTOFOLETTI, Rogério. Padrões de manipulação no jornalismo brasileiro: fake news e a crítica de Perseu Abramo 30 anos depois. Rumores, v. 12, n.23, jan./ jun., 2018.

ERC. A desinformação: contexto europeu e nacional. Disponível em: https://www.parlamento.pt/ Documents/2019/abril/desinformacao_contextoeuroeunacional-ERC-abril2019.pdf. Acesso em: 30 de julho de 2019.

FOUCAULT, M. Em defesa da sociedade. São Paulo: Martins Fontes, 2010.

FOUCAULT, M. Segurança, território e população: curso dado no Collège de France (19771978). São Paulo: Martins Fontes, 2008.

FOUCAULT, M. Vigiar e punir. Petrópolis: Vozes, 1987.

FROTA, M.G. da Cunha; BARBOSA NETO, P.A. Regimes de Informação e Regimes Internacionais de Direitos Humanos: Perspectivas Teóricas e Metodológicas. In: ENCONTRO NACIONAL DE PESQUISA EM CIÊNCIA DA INFORMAÇÃO, S. 2014, ECI/UFMG, 2014. Anais.... Disponível em: http:// enancib2014.eci.ufmg.br/documentos/anais/anais-gt5. Acesso em: 17 nov. 2017.

MARSHALL, Jonathan Paul. Disinformation Society, Communication and Cosmopolitan Democracy. Cosmopolitan Civil Societies Journal, v. 9, n. 2, p. 1-24, 2017.

NATHANSOHN, B.M. 0 regime de informação entre tratamento humanitário e a vigilância para 0 controle: ecos da gramática global no sistema de refúgio brasileiro. 2018 Tese (Dout. em Ci. da Inf.). IBICT/UFRJ: Rio de Janeiro, 2018.

PARENTI, Michael. Monopoly media manipulation. Maio de 2001. Disponível em: www.mi chaelparenti.org/monopolymedia.htm. Acesso em: junh. 2019.

PÓVOA NETO. Território e mobilidade: barreiras físicas como dispositivos de política migratória na atualidade. In: NATAL, Jorge. (Org.). Território e planejamento: 40 anos de PUR/UFRJ. Rio de Janeiro: IPPUR-UFRJ; Letra Capital, 2011. p. 123-147.

RAISING barriers: a new age of walls. In: The Washington Post, 12 out. 2016. Disponível em: https://www.washingtonpost.com/graphics/world/border-barriers/global-illegalimmigrationprevention/?noredirect=on. Acesso em: 20 fev. 2018.

ROMANO, Vicente. La información de la mentalidad sumisa. Barcelona, El Viejo topo, 2007.

SERRANO, Pascual. Desinformação: como os meios de comunicação ocultam o mundo. Rio de Janeiro: Espalhafato, 2010.

THE ECONOMIST. More neighbours make more fences. 07 de janeiro de 2016. Disponível em: http:// www.economist.com/blogs/graphicdetail/2016/01/daily-chart-5. Acesso em: 19 out. 2016. 
UNHCR/ACNUR. Disponível em: http://www.acnur.org/portugues/recursos/estatisticas/. Acesso: 30 jul. 2019.

VOLKOFF, Vladimir. Une petite histoire de la désinformation: du cheval de Troie à Internet. Monaco: Editions du Rocher, 1999. 